\title{
Developmental stability of the mink Mustela vison under the impact of PCB
}

\author{
Vyacheslav I. BORISOV, Alexander S. BARANOV, Alexey V. VALETSKY \\ and Vladimir M. ZAKHAROV
}

\begin{abstract}
Borisov V. I., Baranov A. S., Valetsky A. V. and Zakharov V. M. 1997. Developmental stability of the mink Mustela vison under the impact of PCB. [In: Developmental homeostasis in natural populations of mammals: phenetic approach. V. M. Zakharov and A. V. Yablokov, eds]. Acta Theriologica, Suppl. 4: 17-26.

Females of the American mink Mustela vison Schreber, 1777 were fed on various fractions of comercial PCB. Developmental stability of their progeny was studied. Developmental stability was measured by the value of fluctuating asymmetry, and the frequency of phenodeviants of osteological and dermatoglyphic characters. All these measures proved to be significantly higher in the experimental intoxicated groups than in the control group, thus indicating deterioration of developmental stability from PCB.

N. K. Koltzov Institute of Developmental Biology, Russian Academy of Science, Vavilov Str. 26, Moscow, 117808 Russia

Key words: Mustela vison, non-metric traits, fluctuating asymmetry, developmental stability, environmental stress, $\mathrm{PCB}$
\end{abstract}

\section{Introduction}

A decrease of seal populations in the Baltic Sea was documented during the 20th century (Helander 1989, Tormosov and Esipenko 1989, Olsson et al. 1992). A decrease in reproductive capacity (Olsson 1989), as well as an increase in pathological changes in various organs (Bergman and Olsson 1989, Bergman et al. 1989), was observed in these populations. We also found a deterioration in the condition of the Baltic populations of seals, as measured by developmental stability (Zakharov et al. 1989a, b, Zakharov and Yablokov 1990, Zakharov et al. 1997). Such a deterioration of the seal populations was suggested as being mainly caused by increased levels of various pollutants, organochlorines in particular (Helle et al. 1976a, b, Olsson and Reutergrdh 1986, Olsson et al. 1989).

Experiments on the impact of commercial polychlorinated biphenyls on the mammal organism function, and on the reproductive capacity in particular, were conducted on the American mink Mustela vison Shreber, 1777, as a model, by Swedish researchers in 1988 . They studied reproductive outcome of female minks given daily doses of commercial PCB or fractions of it. The result of the impact 
was estimated by the duration of pregnancy, the number of dead and live whelps born, their weight, the number of implantation scars and resorbed fetuses, as well as some histological and biochemical parameters (cf Brunström 1992, Edquist et al. 1992, Kihlström et al. 1992).

The aim of this study was to conduct a morphological analysis of the experimental material from the Swedish mink experiment, kindly presented to us by colleagues from the National Swedish Museum of Natural History. We sought to estimate the impact of various fractions of PCB on the developmental stability of the mink progeny and to test the hypothesis that also in seals PCB must cause a decrease in developmental stability.

\section{Material and methods}

New-born whelps born from female mink exposed to various fractions of the commercial product Clophen A50 were studied. The experiment on the non-fractionated product was not used for the study, as all females aborted during this exposure. Two-year-old female minks of a standard breed were allocated into 6 groups of 10 animals each.

One group was used as a control (group 1). Experimental mink dams were fed on PCB fractions starting about 35 days before mating and continuing for 50 days thereafter. The commercial PCB product Clophen A50 was separated into 4 fractions studied (Table 1):

-2-4-ortho-CBs: CBs with two or more chlorine atoms in the ortho positions to the biphenyl bond, this fraction corresponds to approximately $80 \%$ of Clophen A50 (experimental group 2);

- 1-ortho-CBs: CBs with only one chlorine atom in ortho-positions, approximately $20 \%$ of Clophen A50 (group 3);

- 0-ortho-CBs: CBs without chlorine atoms in an ortho-position, less than $1 \%$ of Clophen A50 (group 4 was given the mixture fractionated from the commercial PCB product while group 5 was exposed to the synthesized mixture);

- the bi- and tricyclic contaminants including polychlorinated naphthalenes (PCN) and polychlorinated dibenzofurans (PCDF) found in Clophen A50, the concentration of PCDF was $1.3 \mu \mathrm{g} / \mathrm{g}$ Clophen A50 (group 6).

Daily dose of Clophen A50 was $2 \mathrm{mg}$ per animal. The amount of each separate fraction was given according to its proportion in Clophen A50. For the details of the experiment see Kihlström et al. (1992).

Table 1. Sample size of groups of the mink Mustela vison whelps treated with different PCB fractions.

\begin{tabular}{llcc}
\hline $\begin{array}{l}\text { Experimental } \\
\text { group number }\end{array}$ & $\begin{array}{l}\text { Type of } \\
\text { CBs given }\end{array}$ & $\begin{array}{c}\text { Number of live } \\
\text { whelps born }\end{array}$ & $\begin{array}{c}\text { Number of dead } \\
\text { whelps born }\end{array}$ \\
\hline 1 & Control & 24 & 22 \\
$1 \mathrm{a}$ & Control & - & 10 \\
2 & 2-4-ortho- & 21 & - \\
$2 \mathrm{a}$ & 2-4-ortho- & 26 & \\
3 & 1-ortho- & 24 & 27 \\
4 & 0-ortho- & 34 & \\
5 & 0-ortho- (synthesized) & bi-, tricyclic contaminants & \\
6
\end{tabular}


Whelps born alive have been used in this study. Moreover, the dead whelps born from the control group 1 and the experimental group 2 (marked $1 \mathrm{a}$ and $2 \mathrm{a}$ - respectively) were studied for comparison (Table 1).

Various bilateral characters were chosen for the comprehensive estimation of morphogenetic stability. All characters were scored on the left and on the right sides of the body.

The number of foramina as apertures through the bone for the nerves and blood vessels on different skull bones were considered as separate characters (cranial characters 1-7, Fig. 1). The number of main and accessory palatine ridges were counted (palatine characters $8-10$, Fig. 2a). The ridges and granules in the muzzle dermatoglyph were also counted (dermatoglyphic characters 11-14, Fig. 2b).

Fluctuating asymmetry and frequency of phenodeviants were used as developmental stability measures. Non-directional alterations from perfect symmetry for the 14 characters were used to estimate fluctuating asymmetry. All these characters, as well as their asymmetries, proved to be uncorrelated with one another. It was established through the calculation of coefficient of correlation for all possible paired comparisons of the characters used. Fluctuating asymmetry was estimated by the variance of the absolute $(l-r)$ and scaled $(l-r) /(l+r)$ differences between the character values on the left and on the right sides of the body. As the pattern of intergroup variation obtained for both indices proved to be the same, only the results of the study of the variance of $(l-r)$ are presented in this paper.

Mean number of asymmetrical characters per individual for each character set, as well as for all characters, was used as an integrated measure of developmental stability. Mean number of small

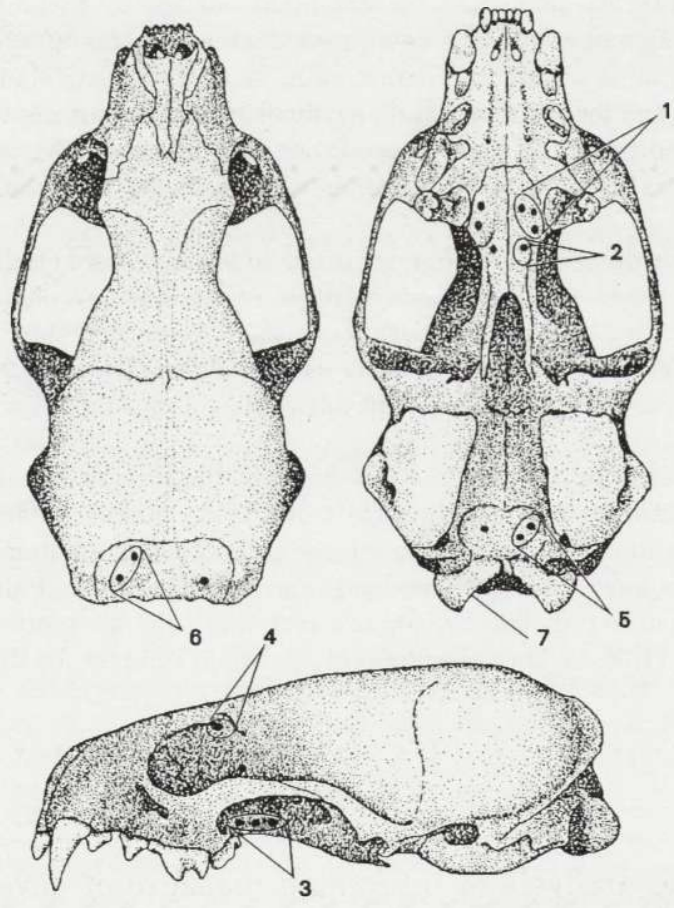

Fig. 1. Cranial characters (Numbers 1-7), expressed as a number of foramina, examined in the mink Mustela vison whelps: 1 - foramen palatinum anterior [1-2], 2 - foramen palatinum posterior [0-1], 3 -foramen infraorbitalis accessorius [2-3], 4 -foramen supraorbitalis [1], 5 -foramen basioccipitalis [0], 6 - foramen supraoccipitale [0], 7 - foramen hypoglossum infracondilaris [2]. The most common variant(s) of the character (number of foramina) is given in brackets []. 


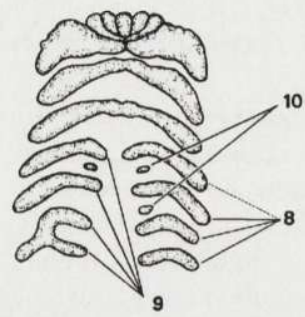

a

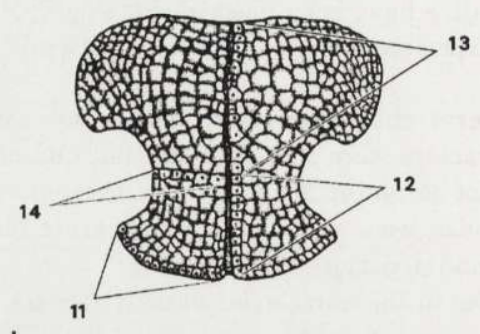

b

Fig. 2. Scheme of the palatine ridge pattern (a) and muzzle dermatoglyphic pattern (b) of the mink Mustela vison whelp. Palatine characters examined: 8 - the outer palatine ridge number [7], 9 - the inner palatine ridge number [4], 10 - the number of accessory ridges and granules [0]. Dermatoglyphis charcters: 11 - the labial ridge number [12-15], 12 - the inner ridge number from the lip to the pattern center [6-8], 13 - the inner ridge number from the center to the upper margin of the pattern [4-6], 14 - the ridge number from the pattern center to the nostril [5-6]. The most common variant(s) of the ridge number is given in brackets [].

phenodeviants per individual was used as another integrated measure of developmental stability. To detect small phenodeviants we identified the dominant variant or variants for each character (as presented in Figs 1 and 2), and scored any deviations, such as absence of a foramen typically present, or the presence of two foramina when one is the norm, as phenotypic deviants. We used the same set of characters that were used for the fluctuating asymmetry study. This approach has been previously used for various taxa, and generally a good correlation has been detected between the mean number of asymmetrical characters and mean number of phenotypic deviants (Zakharov 1985, 1987, Zakharov et al. 1989a, b, 1991).

To reveal more serious disturbances of morphogenetic processes, we studied the frequency of large phenodeviants (obvious developmental abnormalities in various morphological structures). Large phenodeviants were: A - division of the parietal bone, B - presence of the accessory parietal bone, C - irregularity in the ridge pattern of the muzzle dermatoglyph, D - abnormality or absence of the central line in the muzzle dermatoglyphic pattern, E - abnormal pigmentation of the muzzle dermatoglyph.

Student's $t$-test was used to compare the difference in the integrated measures of developmental stability: mean number of asymmetrical characters and mean number of small phenodeviants. $t$-test with $\varphi$-Fishers transformation was used for the large phenodeviant frequency analysis. According to earlier established recommendations (Vrijenhoek and Lerman 1982, Palmer and Strobeck 1986, Zakharov et al. 1991), non-parametric Friedman's test was used as another approach to check the concordance of changes in the variance of asymmetry between samples for the set of characters (Sokal and Rohlf 1981).

\section{Results}

The results of the analysis of integrated measure of developmental stability, the mean number of asymmetrical characters, are presented in Table 2. Groups $2-5$ as well as the two samples of dead whelps ( $1 \mathrm{a}$ and $2 \mathrm{a}$ ) had higher values ( $t$-test: $p<0.05$ ) than groups 1 and 6 . The pattern of the intergroup variation was the same for each set of characters and for the whole set of the characters. 
Table 2. Mean number $( \pm \mathrm{SE})$ of the asymmetrical characters in various experimental groups of the mink Mustela vison whelps (see Table 1).

\begin{tabular}{lcccc}
\hline $\begin{array}{l}\text { Experimental } \\
\text { group } \\
\text { number }\end{array}$ & $\begin{array}{c}\text { Cranial } \\
\text { characters }\end{array}$ & $\begin{array}{c}\text { Palatine } \\
\text { characters }\end{array}$ & $\begin{array}{c}\text { Dermatoglyphic } \\
\text { characters }\end{array}$ & $\begin{array}{c}\text { All } \\
\text { characters }\end{array}$ \\
\cline { 2 - 5 } 1 & $2.64 \pm 0.45$ & $0.74 \pm 0.18$ & $2.22 \pm 0.20$ & $5.69 \pm 0.71$ \\
$1 \mathrm{a}$ & $4.00 \pm 0.35$ & $1.47 \pm 0.20$ & $3.06 \pm 0.26$ & $8.40 \pm 0.55$ \\
2 & $4.31 \pm 0.22$ & $1.24 \pm 0.24$ & $2.95 \pm 0.21$ & $8.47 \pm 0.48$ \\
$2 \mathrm{a}$ & $3.56 \pm 0.38$ & $1.25 \pm 0.36$ & $3.50 \pm 0.34$ & $8.50 \pm 0.50$ \\
3 & $3.21 \pm 0.31$ & $1.48 \pm 0.24$ & $3.38 \pm 0.17$ & $8.16 \pm 0.49$ \\
4 & $3.15 \pm 0.33$ & $1.58 \pm 0.22$ & $3.16 \pm 0.16$ & $7.88 \pm 0.51$ \\
5 & $2.95 \pm 0.30$ & $1.74 \pm 0.17$ & $2.68 \pm 0.19$ & $7.27 \pm 0.41$ \\
6 & $2.21 \pm 0.18$ & $0.48 \pm 0.12$ & $2.26 \pm 0.18$ & $5.00 \pm 0.30$ \\
\hline
\end{tabular}

Similar result was obtained by the analysis of the sum of ranks for the asymmetry variance (Table 3 ). It was significantly higher in the groups $2-5$ than in the groups 1 and 6 . Values of fluctuating asymmetry in two samples of dead whelps born from the control (1a) and experimental (2a) groups were similar to the level of the live whelps born from the groups $2-5$. The same pattern for the intergroup differences was observed for each of the three sets of the characters and for the whole material. Non-parametric Friedman's test revealed significant intersample changes in fluctuating asymmetry. It is equal for the cranial characters (characters 1-7): $21.14(p<0.01)$, for the palatine characters (characters 8-10): $15.22(p<0.05)$, for the dermatoglyphic characters (characters 11-14): $17.25(p<0.01)$, and for the whole set of the characters (characters 1-14): 35.05 $(p<0.001)$, respectively.

Table 3. Sum of ranks for the fluctuating asymmetry variance of (l-r) in various experimental groups of the mink Mustela vison whelps (see Table 1).

\begin{tabular}{lcccc}
\hline $\begin{array}{l}\text { Experimental } \\
\text { group } \\
\text { number }\end{array}$ & $\begin{array}{c}\text { Cranial } \\
\text { characters }\end{array}$ & $\begin{array}{c}\text { Palatine } \\
\text { characters }\end{array}$ & $\begin{array}{c}\text { Dermatoglyphic } \\
\text { characters }\end{array}$ & $\begin{array}{c}\text { All } \\
\text { characters }\end{array}$ \\
\cline { 2 - 5 } 1 & 24 & 7 & 8 & 39 \\
$1 \mathrm{a}$ & 41 & 18 & 18 & 77 \\
2 & 47 & 10 & 22 & 79 \\
$2 \mathrm{a}$ & 32 & 17 & 16 & 65 \\
3 & 40 & 18 & 23 & 81 \\
4 & 34 & 14 & 31 & 57 \\
5 & 18 & 21 & 18 & 27 \\
\hline
\end{tabular}


Table 4. Mean number $( \pm \mathrm{SE})$ of small phenodeviants in various experimental groups of the mink Mustela vison whelps (see Table 1).

\begin{tabular}{lcccc}
\hline $\begin{array}{l}\text { Experimental } \\
\text { group } \\
\text { number }\end{array}$ & $\begin{array}{c}\text { Cranial } \\
\text { characters }\end{array}$ & $\begin{array}{c}\text { Palatine } \\
\text { characters }\end{array}$ & $\begin{array}{c}\text { Dermatoglyphic } \\
\text { characters }\end{array}$ & $\begin{array}{c}\text { All } \\
\text { characters }\end{array}$ \\
\cline { 2 - 5 } 1 & $2.86 \pm 0.35$ & $1.40 \pm 0.19$ & $1.78 \pm 0.19$ & $6.30 \pm 0.55$ \\
1a & $3.93 \pm 0.27$ & $2.65 \pm 0.22$ & $3.06 \pm 0.34$ & $9.46 \pm 0.58$ \\
2 & $4.25 \pm 0.37$ & $2.00 \pm 0.28$ & $2.60 \pm 0.27$ & $8.70 \pm 0.67$ \\
$2 \mathrm{a}$ & $3.67 \pm 0.41$ & $2.75 \pm 0.60$ & $2.00 \pm 0.37$ & $8.75 \pm 1.30$ \\
3 & $3.00 \pm 0.34$ & $2.60 \pm 0.27$ & $4.00 \pm 0.31$ & $9.72 \pm 0.53$ \\
4 & $2.70 \pm 0.38$ & $2.70 \pm 0.20$ & $3.79 \pm 0.35$ & $8.88 \pm 0.69$ \\
5 & $2.04 \pm 0.24$ & $2.89 \pm 0.17$ & $3.10 \pm 0.36$ & $7.63 \pm 0.55$ \\
6 & $2.16 \pm 0.30$ & $1.26 \pm 0.16$ & $2.00 \pm 0.17$ & $5.53 \pm 0.43$ \\
\hline
\end{tabular}

Similar patterns of intergroup variation were found for mean number of small phenodeviants for each of the three groups of the characters as well as for the whole set of the characters under study (Table 4). Control group 1 and experimental group 6 were characterized by lower level of small phenodeviants $(t$-test: $p<0.05$ ) in comparison with all others, including the sample of dead whelps from the control group.

The results of the study of large phenodeviants are presented in Table 5 . Intergroup differences for the two phenodeviants (A and $\mathrm{C}$ ) are similar to the pattern revealed for the other developmental stability measures, their frequencies are higher $(t$-test with $\varphi$-Fishers transformation: $p<0.05)$ in experimental groups

Table 5. Frequency (\%) of the large phenodeviants in various experimental groups of the mink Mustela vison whelps (see Table 1). Large phenodeviants: A - division of the parietal bone, B - presence of the accessory parietal bone, $\mathrm{C}$ - curvature of the ridge rows in the muzzle dermatoglyph pattern, D - curvature or absence of the central line in the muzzle dermatoglyphic pattern, E - partial or complete depigmentation of commonly colored muzzle dermatoglyph.

\begin{tabular}{lrrrrr}
\hline \multirow{2}{*}{$\begin{array}{l}\text { Experimental } \\
\text { group number }\end{array}$} & \multicolumn{5}{c}{ Phenodeviants } \\
\cline { 2 - 6 } & $\mathrm{A}$ & $\mathrm{B}$ & $\mathrm{C}$ & $\mathrm{D}$ & $\mathrm{E}$ \\
\hline 1 & 8.3 & 0.0 & 4.0 & 0.0 & 19.0 \\
$1 \mathrm{a}$ & 27.3 & 52.6 & 21.1 & 47.6 & 61.9 \\
2 & 19.0 & 57.1 & 22.2 & 37.5 & 63.6 \\
$2 \mathrm{a}$ & 30.0 & 30.0 & 22.2 & 20.2 & 90.0 \\
3 & 15.4 & 65.3 & 30.7 & 69.2 & 76.9 \\
4 & 30.4 & 69.3 & 45.8 & 83.3 & 62.5 \\
5 & 28.0 & 52.0 & 33.6 & 89.9 & 55.5 \\
6 & 2.9 & 46.7 & 8.8 & 23.5 & 41.2 \\
\hline
\end{tabular}


$2-5$, than in the control group 1 and in experimental group 6 , while the frequency for the three other phenodeviants (B, D and E) prove to be significantly higher in all experimental groups (2-6) than in the control one.

\section{Discussion}

Developmental stability was established as a measure of environmental stress (Valentine et al. 1973, Ames et al. 1979, Jagoe and Haines 1985, Pankakoski 1985, Zakharov 1989, Shaikin 1992, Freeman et al. 1994). For example, deterioration of developmental stability, as seen in the increased fluctuating asymmetry of various morphological characters, has been found in small mammal populations exposed to heavy metal (Pankakoski et al. 1992) and in fish exposed to DDT (Valentine and Soulé 1973). Likewise, the serious decrease in developmental stability in the Baltic seal populations was thought to be caused by increased levels of organochlorines (Olsson et al. 1989). To test the hypothesis that the developmental stability of seals decreases under the impact of PCB, we studied this effect on the mink.

In previous studies, the negative impact of commercial PCB as well as the combinations of its fractions on reproductive capacity has been revealed (Bäcklin and Bergman 1992, Bergman et al. 1992, Kihlström et al. 1992). No statistically significant impact on reproduction capacity has been found for the single fraction. Indications of adverse effect of a single fraction impact have been found only for the biochemical markers of homeostasis in pregnant females; these include cytochrome P-450 - dependent enzyme activity, vitamin A levels, and blood parameters (Brunström 1992, Edqvist et al. 1992, Hakansson et al. 1992).

Our study revealed increased fluctuating asymmetry and frequency of phenodeviants in the progeny of female mink exposed to the majority of separate fractions of commercial PCB. The same pattern of intergroup variation was found for the various measures of developmental stability in such different morphological structures as skull foramina and dermatoglyphic pattern. The concordance of all the data suggests that the deterioration in the overall developmental stability of an organism under the impact of different PCB fractions can be revealed in various, even uncorrelated, phenotypic traits.

We do not have enough evidence to establish deterioration in overall developmental stability under the impact of the bi- and tricyclic contaminants (group 6). In all previous studies, no negative impact has been established; in fact, there is some indication of improvement of an organisms condition under its influence (Bergman et al. 1992, Edqvist et al. 1992, Kihlström et al. 1992). Neither integrated measures of developmental stability have found differences between this group and the control (Tables 2 and 4). An increase of the frequency of some phenodeviants, however, indicates an alteration from the norm in morphogenetic processes under this impact as well. 
Serious deterioration of developmental stability in the dead whelps from the control group (group 1a) was similar to that seen in the progeny of the exposed females (groups 2-5). This provides support for the notion that developmental stability is an important measure of an organisms condition. Changes in the condition of an organism, caused by various factors that will lead to its elimination from the population, is accompanied by a decrease in developmental stability. The similarity of developmental instability for the live and dead whelps born to exposed females (groups 2 and 2a) provides evidence that this characteristic indicates a change in the condition of an organism, but can not be considered the cause of its death. All these data allow us to conclude that developmental stability is a sensitive indicator of environmental stress, revealing not only serious irreversible alteration in an organisms condition, but also its initial change under the impact of stress.

Thus, the results of this study demonstrate the deterioration in developmental stability of the progeny of the female mink exposed to PCB. Certain negative consequences were observed for all fractions of the commercial product Clophen A50, including the fractions from which negative impacts had not been seen by other approaches. All these data allow us to recommend developmental stability as a sensitive measure the impact of stress.

Our data supports the hypothesis that the deterioration in developmental stability in seal populations in the Baltic (Zakharov and Yablokov 1990, Zakharov et al. 1997) may have been also caused by the increased level of organochlorines.

Acknowledgements: We are very grateful to Prof M. Olsson from the National Swedish Museum of Natural History for the experimental material on minks kindly presented for the study. We are also grateful to Dr I. Pavlinov from the Zoological Museum of the Moscow State University for the recommendation on the proper method for the mink whelp skull cleaning. We are very grateful to Dr J. H. Graham and three anonymous referees provided very helpful comments and corrections of English.

\section{References}

Ames L. J., Felley J. D. and Smith M. H. 1979. Amounts of asymmetry in Centrarchid fish inhabiting heated and non-heated reservoirs. Trans-American Fisheries Society 108: 489-495.

Bäcklin B.-M. and Bergman $\AA$. 1992. Morphological aspects on the reproductive organs in female mink (Mustela vison) exposed to polychlorinated biphenyls and fractions thereof. Ambio 21: 596-601.

Bergman Å., Bäcklin B.-M., Järplid B., Grimelius L. and Wilander E. 1992. Influence of commercial polychlorinated biphenyls and fractions thereof on liver histology in female mink (Mustela vison). Ambio 21: 591-595.

Bergman $\AA$. and Olsson M. 1989. Pathology of Baltic gray and ringed seal males. Report regarding animals sampled 1977-1985. [In: Influence of human activities on the Baltic ecosystem. Proceedings of Soviet-Swedish Symposium. A. V. Yablokov and M. Olsson, eds]. Gidrometeoizdat, Leningrad: $74-86$.

Bergman $\AA$., Olsson M. and Reiland S. 1989. High frequency of skeletal deformities in skulls of the Baltic gray seal. [In: Influence of human activities on the Baltic ecosystem. Proceedings of 
Soviet-Swedish Symposium. A. V. Yablokov and M. Olsson, eds]. Gidrometeoizdat, Leningrad: $87-95$.

Brunström B. 1992. Induction of cytochrome P-450 - dependent enzyme activities in female mink (Mustela vison) and their kits by technical PCB preparations and fractions thereof. Ambio 21 $585-587$.

Edqvist L-E., Madej A. and Forsberg M. 1992. Biochemical blood parameters in pregnant mink fed PCB and fractions of PCB. Ambio 21: 577-581.

Freeman D. C., Graham J. H. and Emlen J. M. 1994. Developmental stability in plants: symmetries, stress and epigenesis. [In: Developmental instability: its origins and evolutionary implication T. A. Markow, ed]. Kluwer Academical Publishers, Dordrecht: 99-122.

Håkansson H., Manzoor E. and Ahlborg U. G. 1992. Effects of technical PCB preparations and fractions there of on vitamin A levels in the mink (Mustela vison). Ambio 21: 588-590.

Helander B. 1989. Survey of gray seal Halichoerus grypus and harbour seal Phoca vitulina along the Swedish Baltic cost 1975-1984. [In: Influence of human activities on the Baltic ecosystem. Proceedings of Soviet-Swedish Symposium. A. V. Yablokov and M. Olsson, eds]. Gidrometeoizdat, Leningrad: $10-21$.

Helle E., Olsson M. and Jensen S. 1976a. DDT and PCB levels and reproduction in ringed seal from the Bothnian Bay. Ambio 5: 188-189.

Helle E., Olsson M. and Jensen S. 1976b. PCB levels correlated with pathological changes in seal uteri. Ambio 5: 261-263.

Jagoe C. H. and Haines T. A. 1985. Fluctuating asymmetry in fishes inhabiting acidified and unacidified lakes. Canadian Journal Zoology 83: 130-138.

Kihlström J. E., Olsson M., Ensen S., Johansson Å., Ahlbom J. and Bergman Å. 1992. Effects of PCB and different fractions of $\mathrm{PCB}$ on the reproduction of the mink (Mustela vison). Ambio 21: $563-569$.

Olsson M. 1989. The gray seal breeding enclosure at Forsmark, Sweden. [In: Influence of human activities on the Baltic ecosystem. Proceedings of Soviet-Swedish Symposium. A. V. Yablokov and M. Olsson, eds]. Gidrometeoizdat, Leningrad: 58-59.

Olsson M., Karlsson B. and Ahnland E. 1992. Seals and seal protection: a presentation of a Swedish research project. Ambio 21: 494-496.

Olsson M. and Reutergrdh L. 1986. DDT and PCB pollution trends in the Swedish aquatic environment. Ambio 15: 103-109.

Olsson M., Reutergrdh L. and Yablokov A. V. 1989. DDT and PCB levels in ringed seal (Pusa hispida) from lake Ladoga and the gulf of Bothnia. [In: Influence of human activities on the Baltic ecosystem. Proceedings of Soviet-Swedish Symposium. A. V. Yablokov and M. Olsson, eds]. Gidrometeoizdat, Leningrad: 117-129.

Palmer R. A. and Strobeck C. 1986. Fluctuating asymmetry: measurement, analysis, patterns. Annual Review of Ecology and Systematics 17: 391-421.

Pankakoski E. 1985. Epigenetic asymmetry as an ecological indicator in muskrats. Journal of Mammalogy 66: 52-57.

Pankakoski E., Koivisto I. and Hyvarinen H. 1992. Reduced developmental stability as an indicator of heavy metal pollution in the common shrew Sorex araneus. Acta Zoologica Fennica 191: 137-144.

Shaikin A. V. 1992. Developmental stability and phenotypic diversity of color pattern in perch (Perca fluviatilis L.) from different parts of its range. Acta Zoologica Fennica 191: 151-158.

Sokal R. R. and Rohlf F. J. 1981. Biometry. Freeman, San Francisco: 1-859.

Tormosov D. D. and Esipenko A. G. 1989. Aircraft counting of seals in the gulfs of Finland and Riga in spring 1985 and some details of the counting method. [In: Influence of human activities on the Baltic ecosystem. Proceedings of Soviet-Swedish Symposium. A. V. Yablokov and M. Olsson, eds]. Gidrometeoizdat, Leningrad: 5-9.

Valentine D. W. and Soulé M. 1973. Effect of p,p-DDT on developmental stability of pectoral fin rays in the grunion, Leuresthes tenuis. Fishery Bulletin 71: 921-925. 
Valentine D. W., Soulé M. E. and Samollow P. 1973. Asymmetry analysis in fishes: a possible statistical indicator of environmental stress. Fishery Bulletin 71: 357-370.

Vrijenhoek R. C. and Lerman S. 1982. Heterozygosity and developmental stability under sexual and asexual breeding systems. Evolution 36: 768-776.

Zakharov V. M. 1985. Analysis of homeorhesis in ontogenetic, population and evolutionary aspects. [In: Thermodynamics and regulation of biological processes. I. Lamprecht and A. I. Zotin, eds]. Walter de Gruyter, Berlin: 509-519.

Zakharov V. M. 1987. [Animal asymmetry: population-phenogenetic approach]. Nauka, Moskva: 1-216. [In Russian]

Zakharov V. M. 1989. Future prospects for population phenogenetics. Soviet Science Reviews, Section F 4 (3): 1-79.

Zakharov V. M., Esipenko A. G. and Filatov I. E. 1989a. Are there differences in the level of developmental stability between the Baltic and Ladoga populations of ringed seal (Pusa hispida botnica and $P . h$. ladogensis)? [In: Influence of human activities on the Baltic ecosystem. Proceedings of Soviet-Swedish Symposium. A. V. Yablokov and M. Olsson, eds]. Gidrometeoizdat, Leningrad: 109-116.

Zakharov V. M., Olsson M., Yablokov A. V. and Esipenko A. G. 1989b. Does environmental pollution affect the developmental stability of the Baltic gray seal (Halichoerus grypus)? [In: Influence of human activities on the Baltic ecosystem. Proceedings of Soviet-Swedish Symposium. A. V. Yablokov and M. Olsson, eds]. Gidrometeoizdat, Leningrad: 96-108.

Zakharov V. M., Pankakoski E., Sheftel B. I., Peltonen A. and Hanski I. 1991. Developmental stability and population dynamics in the common shrews, Sorex araneus. American Naturalist 138: 797-810.

Zakharov V. M., Valetsky A. V. and Yablokov A. V. 1997. Dynamics of developmental stability of seals and pollution in the Baltic Sea. [In: Developmental homeostasis in natural populations of mammals: phenetic approach. V. M. Zakharov and A. V. Yablokov, eds]. Acta Theriologica, Suppl. 4: 9-16.

Zakharov V. M. and Yablokov A. V. 1990. Skull asymmetry in the Baltic gray seal: effects of environmental pollution. Ambio 19: 266-269.

Received 11 October 1995, revised 10 October 1996, accepted 15 March 1997. 